\title{
Parametric Investigation and Thermoeconomic Optimization of a Combined Cycle for Recovering the Waste Heat from Nuclear Closed Brayton Cycle
}

\author{
Lihuang Luo, Hong Gao, Chao Liu, and Xiaoxiao Xu \\ Key Laboratory of Low-Grade Energy Utilization Technologies and Systems of Ministry of Education, \\ College of Power Engineering, Chongqing University, Chongqing 400030, China
}

Correspondence should be addressed to Hong Gao; gaohong@cqu.edu.cn

Received 19 April 2016; Accepted 22 June 2016

Academic Editor: Xiangdong Li

Copyright (C) 2016 Lihuang Luo et al. This is an open access article distributed under the Creative Commons Attribution License, which permits unrestricted use, distribution, and reproduction in any medium, provided the original work is properly cited.

\begin{abstract}
A combined cycle that combines AWM cycle with a nuclear closed Brayton cycle is proposed to recover the waste heat rejected from the precooler of a nuclear closed Brayton cycle in this paper. The detailed thermodynamic and economic analyses are carried out for the combined cycle. The effects of several important parameters, such as the absorber pressure, the turbine inlet pressure, the turbine inlet temperature, the ammonia mass fraction, and the ambient temperature, are investigated. The combined cycle performance is also optimized based on a multiobjective function. Compared with the closed Brayton cycle, the optimized power output and overall efficiency of the combined cycle are higher by $2.41 \%$ and $2.43 \%$, respectively. The optimized LEC of the combined cycle is $0.73 \%$ lower than that of the closed Brayton cycle.
\end{abstract}

\section{Introduction}

With the development of the world economy, the total energy consumption increases steadily. The consumption of the energy, especially fossil energy resources, causes and accelerates the occurrence of many environmental problems. Nuclear energy is an efficient energy source that plays an important role in current energy demand. Because of its inherent safety, the high temperature gas-cooled reactor (HTGR) has attracted many attentions of the researchers. To ensure the high efficiency of nuclear power plant, reasonable thermodynamic cycle should be used. Despite the higher efficiency of HTGR, a large amount of waste heat is discharged from the precooler of the nuclear closed Brayton cycle. Thus, research topics focus on recovery and utilization of this low grade thermal energy.

At present, the waste heat of the closed Brayton cycle can be recovered by several ways, as follows: desalination, Organic Rankine Cycle (ORC), Kalina cycle, and ammoniawater combined power/cooling cycle. Soroureddin et al. [1] proposed the utilization of this waste heat for power production by using ORC. Dardour et al. [2] proposed and analyzed the utilization of waste heat from GT-MHR and PBMR reactors for nuclear desalination of sea water. Since Kalina [3] introduced the Kalina cycle with the ammoniawater mixture as the working fluid, at least 30 new cycles based on the Kalina cycle have been presented. Goswami [4] also put forward a combined power/cooling cogeneration cycle with ammonia-water mixture as working fluid. For a turbine inlet temperature and pressure of $410 \mathrm{~K}$ and 30 bar, the first law efficiency is $23.54 \%$; such value is much better than ORC or Kalina cycle [5]. Padilla et al. [6] and $\mathrm{Lu}$ and Goswami [7] modified the combined power/cooling cogeneration cycle and studied the effect of key parameters on cycle performance. Pouraghaie et al. [8] revealed that the efficiency of the combined power/cooling cogeneration cycle is much higher than that of a conventional steam Rankine cycle. Demirkaya et al. [9] also found that the combined power/cooling cogeneration cycle has a promising prospect for effective utilization of waste heat because of the reasonably good matching between the temperature profiles of helium and ammonia-water mixture in the boiler.

Meanwhile, many investigations focused on the design and optimization of waste heat recovery system. Some studies 


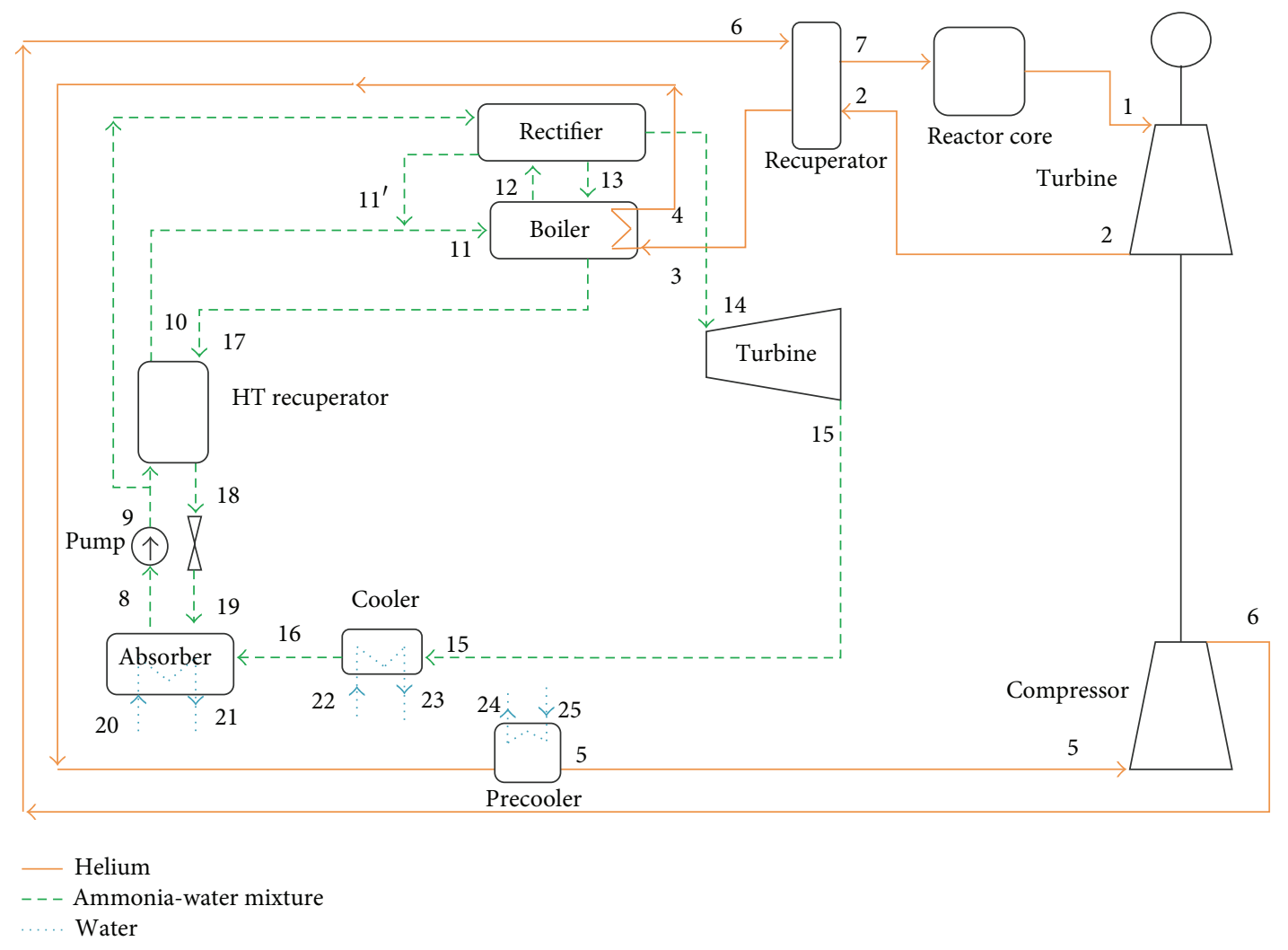

FIGURE 1: Schematic diagram of the combined cycle.

optimized the system according to the net power output, cooling output, first law efficiency, and second law efficiency [8-10]. Shengjun et al. [11] used five indicators: thermal efficiency, exergy efficiency, recovery efficiency, and so on, to optimize the subcritical ORC system and transcritical cycle. Guo et al. [12] used the net power output per unit mass flow rate of hot source, ratio of total heat transfer area to net power output, and electricity production cost to screen working fluids. Coskun et al. [13] proposed four cycles to utilize the geothermal energy and selected one cycle to optimize for the turbine inlet pressure that would generate maximum power output, energy, and exergy efficiencies. Zare et al. [14] carried out an exergoeconomic analysis for a combined GT-MHR/Kalina cycle and compared the performance with the Gas Turbine-Modular Helium Reactor (GT-MHR) plant. Bahlouli et al. [15] perform a parametric study and multiobjective optimization for a bottoming cycle of a trigeneration system with HCCI engine as prime mover. Feng et al. [16] conducted a sensitivity analysis for low temperature ORCs (Organic Rankine Cycles), as well as the thermos-economic comparison between the basic ORC and regenerative ORC.

According to the studies proposed in the public literatures, few investigations focused on the system economic analysis of the combined cycle, especially the evaluation of the levelized energy cost (LEC). In this paper, a combined cycle, in which a power/cooling cogeneration cycle is integrated into the nuclear closed Brayton cycle, is proposed to recover and utilize the waste heat rejected from the precooler of the closed Brayton cycle. Based on a detailed parametric analysis, a multiobjective function $F(X)$, integrating the overall efficiency and the system cost, is used to optimize the thermodynamic and the economic performances of the combined cycle. So the main contributions of the paper are the combined system analysis and multiobjective optimization according to several important parameters.

\section{System Description and Assumptions}

A schematic diagram of the proposed combined cycle is shown in Figure 1. The nuclear core of HTGR is the heat source of the closed Brayton cycle. High pressure helium, as the coolant and the working fluid [2], is heated in the reactor and then enters the gas turbine (state 1) for expansion to convert thermal energy into shaft power, thereby driving the compressors and the electric generator on a single shaft. Since the temperature of the exhaust gas from the turbine (state 2) is still high, a recuperator is equipped to utilize the energy of the exhaust gas from the gas turbine, in which the cold helium from the compressor (state 6) is preheated by the turbine exhaust gas. Then, the exhaust gas flows through the precooler to be cooled (state 5). The cooled helium has low pressure and low temperature after the precooler (state 5) and is compressed by the compressor (state 6). Helium with high pressure and low temperature enters the other side of the recuperator mentioned above to be preheated (state 7) before finally flowing into the reactor core to be heated again to repeat the thermodynamic cycle. 
TABLE 1: Energy relations for the equipment of closed Brayton cycle and AWM cycle.

\begin{tabular}{lll}
\hline Cycle & Equipment & Energy equations \\
\hline & Reactor core & $Q_{\text {core }}=m_{1}\left(h_{1}-h_{7}\right)$ \\
Closed Brayton cycle & Turbine & $W_{T}=m_{1}\left(h_{1}-h_{2 s}\right) \eta_{s, T}$ \\
& Recuperator & $\left(h_{2}-h_{3}\right)=\left(h_{7}-h_{6}\right)$ \\
& Precooler & $Q_{\text {precooler }}=m_{1}\left(h_{4}-h_{5}\right)$ \\
& Compressor & $W_{C}=\frac{m_{1}\left(h_{6 s}-h_{5}\right)}{\eta_{s, C}}$ \\
\hline AWM cycle & Boiler & $m_{1}\left(h_{3}-h_{4}\right)=m_{12} h_{12}+m_{17} h_{17}-m_{11} h_{11}-m_{13} h_{13}$ \\
& Rectifier & $m_{14} h_{14}+m_{13} h_{13}+m_{11^{\prime}}\left(h_{11^{\prime}}-h_{9}\right)=m_{12} h_{12}$ \\
& HT recuperator & $m_{17}\left(h_{17}-h_{18}\right)=m_{10}\left(h_{10}-h_{9}\right)$ \\
& Absorber & $Q_{\text {absorber }}=m_{19} h_{19}+m_{16} h_{16}-m_{8} h_{8}$ \\
Turbine & $W_{T}=m_{14}\left(h_{14}-h_{15 s}\right) \eta_{s, T}$ \\
Cooler & $Q_{\text {cool }}=m_{15}\left(h_{16}-h_{15}\right)$ \\
& Pump & $W_{P}=\frac{m_{8}\left(h_{9 s}-h_{8}\right)}{\eta_{s, P}}$ \\
Throttle valve & $h_{19}=h_{18}$ \\
\hline
\end{tabular}

$\eta_{s, T}, \eta_{s, C}$, and $\eta_{s, P}$ represent the isentropic efficiency of the turbine, the compressor, and the pump, respectively.

The helium flowing out from the gas turbine flows into the hot side of the recuperator where the helium is cooled to about $400 \mathrm{~K}$. To reduce the compressor power consumption, the helium should be cooled to about $300 \mathrm{~K}$ before flowing into the compressor. Thus, the ammonia-water power/cooling cycle (AWM), proposed by Goswami [17] in 2000 , is coupled into this closed Brayton cycle to utilize the waste heat rejected from the precooler. In this situation, the helium flowing out from the hot side of the recuperator enters a boiler before entering the precooler. The heat released by the helium passing through the boiler is the heat resource of the AWM cycle. Then, a part of the HTGR waste heat is recovered for the AWM cycle to produce power. The AWM cycle uses high concentration of ammonia as the working fluid, which can be expanded to a very low temperature in the turbine. The very low temperature ammonia-water mixture provides refrigeration. The net effects are the production of both power and refrigeration.

An ammonia-water mixture (state 8) is pumped to a high pressure (state 9) and heated to boil off ammonia (state 12). The vapor is enriched in ammonia by condensing a part of the vapor in a rectifier (state 14). The condensate is richer in water and returned to the boiler (state 13). The ammonia vapor, which is almost pure ammonia, can be expanded in a turbine to exit at a very low temperature (state 15). After expansion in the turbine to generate power, low temperature ammonia first provides cooling capacity in the cooler (state 16) and is absorbed by low concentration solution from the boiler in an absorber, to form the basic ammonia-water liquid solution to complete the cycle (state 8) [17].

The following assumptions are used in this work:

(1) The system operates in a steady state condition.

(2) Changes in kinetic and potential energies are neglected.

(3) The pressure loss due to the frictional effects is neglected.
(4) The turbine and the pump in the combined cycle have isentropic efficiencies [15].

(5) The ammonia-water solution leaving the absorber (state 8 ) is a saturated liquid at low pressure.

\section{System Modeling}

3.1. Thermodynamic Modeling. A MATLAB code has been developed to carry out the numerical simulations for this combined cycle. The thermodynamic properties of the states in the closed Brayton cycle are evaluated by REFPROP 9.0. The thermodynamic properties of the states of the bottom cycle (AWM cycle) are evaluated by the method proposed by $\mathrm{Xu}$ and Goswami [18]. For thermodynamic analysis, the principles of mass and energy conservations as well as the second law of thermodynamics are applied to each component.

To simplify the calculation, just one operation condition of the closed Brayton cycle is selected according to the literature [19], and the parameters are listed in Table 5.

The energy relations for the equipment of combined cycle are listed in Table 1.

For the combined cycle, the net power output can be defined as follows:

$$
\begin{aligned}
W_{\text {net,Combinedcycle }} & =W_{\text {net }, B}+W_{\text {net }, A W M} \\
& =\left(W_{T}-W_{C}\right)_{B}+\left(W_{T}-W_{P}\right)_{\text {AWM }} .
\end{aligned}
$$

The overall efficiency of the combined cycle is defined as follows:

$$
\eta_{\text {overall,Combinedcycle }}=\frac{W_{\text {net }, B}+W_{\text {net, } \mathrm{AWM}}+W_{\text {cool }}}{Q_{\text {core }}} .
$$


TABLE 2: Comparison between the properties of the present work and those from the published literature [17].

\begin{tabular}{|c|c|c|c|c|c|c|c|c|}
\hline \multirow{2}{*}{ State } & \multirow{2}{*}{$T(\mathrm{~K})$} & \multirow{2}{*}{$p$ (bar) } & \multicolumn{2}{|c|}{$h(\mathrm{~kJ} / \mathrm{kg})$} & \multicolumn{2}{|c|}{$s(\mathrm{~kJ} / \mathrm{kg} \mathrm{K})$} & \multicolumn{2}{|c|}{$x$} \\
\hline & & & $a^{*}$ & $b^{*}$ & $a^{*}$ & $b^{*}$ & $a^{*}$ & $b^{*}$ \\
\hline 8 & 280.0 & 2.0 & -214.1 & -214.4 & -0.1060 & -0.1061 & 0.53 & 0.53 \\
\hline 9 & 280.0 & 30.0 & -211.4 & -211.6 & -0.1083 & -0.1084 & 0.53 & 0.53 \\
\hline 11 & 378.1 & 30.0 & 246.3 & 246.7 & 1.2907 & 1.2924 & 0.53 & 0.53 \\
\hline 12 & 400.0 & 30.0 & 1547.2 & 1549.8 & 4.6102 & 4.6223 & 0.9432 & 0.9451 \\
\hline 13 & 360.0 & 30.0 & 205.8 & 206.1 & 1.1185 & 1.1201 & 0.6763 & 0.6760 \\
\hline 14 & 360.0 & 30.0 & 1373.2 & 1374.1 & 4.1520 & 4.1546 & 0.9921 & 0.9938 \\
\hline 15 & 257.0 & 2.0 & 1148.9 & 1177.6 & 4.5558 & 4.6702 & 0.9921 & 0.9938 \\
\hline 16 & 280.0 & 2.0 & 1278.7 & 1284.6 & 5.0461 & 5.0734 & 0.9921 & 0.9938 \\
\hline 17 & 400.0 & 30.0 & 348.2 & 347.9 & 1.5544 & 1.5563 & 0.4147 & 0.4269 \\
\hline 18 & 300.0 & 30.0 & -119.0 & -120.7 & 0.2125 & 0.2105 & 0.4147 & 0.4269 \\
\hline
\end{tabular}

$a^{*}:$ the thermodynamic properties presented in literature [17].

$b^{*}$ : the thermodynamic properties calculated in this work.

The cooling capacity is converted to equivalent power and can be expressed as

$$
W_{\text {cool }}=\frac{Q_{\text {cool }}}{\text { cop }},
$$

where cop is the coefficient of performance and set as 4 [20].

3.1.1. Verification of Ammonia-Water Thermodynamic Properties. To verify the developed thermodynamic models for AWM cycle, the available data in the literature are used. The comparisons between the simulation results and those reported in the published literature are presented in Table 2. For AWM cycle, the data in Table 2 indicate a very good agreement between simulation results of this paper and those in published literature [17], and the maximum deviation is only $2.5 \%$.

3.2. Economic Modeling. To evaluate the thermoeconomic performance of the combined cycle, levelized energy cost (LEC) is analyzed in this paper. Because the aim of this paper is to evaluate the effect of AWM cycle on the thermodynamic and economic performances of the combined cycle, the HTGR plant (closed Brayton cycle) specific cost is assumed to be $1073 \$ / \mathrm{kW}$ [21]. A cost of $8 \$ / \mathrm{MWh}$ is assumed for nuclear fuel [22].

Then, the capital investment of AWM cycle is calculated. According to the literature [23], the heat exchangers, pump, and turbine contribute largely to the total cost. We assume that all of the heat exchangers in AWM system are shell-andtube heat exchanger $[24,25]$.

The heat exchanger area can be expressed as follows:

$$
\begin{aligned}
A & =\frac{Q}{\left(U \Delta T_{m}\right)}, \\
\Delta T_{m} & =\frac{\left(\Delta T_{\max }-\Delta T_{\min }\right)}{\ln \left(\Delta T_{\max } / \Delta T_{\min }\right)},
\end{aligned}
$$

where $Q$ represents the heat exchanger heat load; $U$ stands for the overall heat transfer coefficient; and $\Delta T_{m}$ is the logarithmic mean temperature difference. The heat transfer
TABLE 3: Heat transfer coefficients for heat exchangers [33].

\begin{tabular}{lc}
\hline Component & Heat transfer coefficient $\left(\mathrm{W} / \mathrm{m}^{2} \mathrm{~K}\right)$ \\
\hline Absorber & 800 \\
Separator & 900 \\
Cooler & 1000 \\
Recuperator & 800 \\
\hline
\end{tabular}

coefficients of some heat exchangers in AWM cycle are shown in Table 3.

The overall heat transfer coefficient of the boiler can be calculated as follows [26]:

$$
\frac{1}{U}=\frac{1}{h_{\mathrm{He}}}+\frac{\delta}{k}+\frac{1}{h_{\mathrm{aw}}}+R
$$

where $h_{\mathrm{He}}$ is the heat transfer coefficient of the helium; $h_{\mathrm{aw}}$ is the ammonia-water heat transfer coefficient and is $2000 \mathrm{~W} /\left(\mathrm{m}^{2} \mathrm{~K}\right)$ [27] according to the characteristic of the cycle; $\delta$ is the thickness of the heat exchanger tube; $k$ is the heat conductivity of the tube; $R$ is the heat resistance of the tube.

The heat transfer coefficient of the helium in the shell is calculated by the following equations:

$$
\begin{aligned}
\mathrm{Nu}_{\mathrm{He}} & =0.023 \operatorname{Re}_{\mathrm{He}}^{0.8} \operatorname{Pr}_{\mathrm{He}}^{0.65}\left(\frac{T_{w}}{T_{b}}\right)^{-c}, \\
c & =0.57-\left(\frac{1.59}{l / d}\right), \\
h_{\mathrm{He}} & =\frac{\mathrm{Nu} \lambda}{d} .
\end{aligned}
$$

For the above equations, Re and Pr are Reynolds number and Prandtl number, respectively. $T_{w}$ and $T_{b}$ are the temperatures of the shell and tube, respectively. $\lambda$ is the thermal conductivity coefficient. $d$ is the diameter or equivalent hydraulic diameter of the heat exchanger. $l$ is the length of the tube. 
TABLE 4: Coefficients required for the cost evaluation for each component [26].

\begin{tabular}{lcccccccccc}
\hline Components & $K_{1}$ & $K_{2}$ & $K_{3}$ & $C_{1}$ & $C_{2}$ & $C_{3}$ & $B_{1}$ & $B_{2}$ & $F_{m}$ & $F_{b m}$ \\
\hline Turbine & 3.15140 & 0.5890 & 0 & 0 & 0 & 0 & 0 & 0 & 0 & 3.50 \\
Pump & 3.5790 & 0.3210 & 0.0290 & 0.1680 & 0.3480 & 0.4840 & 1.80 & 1.51 & 1.80 & Equation (9) \\
Heat exchanger & 3.2138 & 0.2688 & 0.07961 & -0.064991 & 0.05025 & 0.01474 & 1.80 & 1.50 & 1.25 & Equation (9) \\
\hline
\end{tabular}

TABLE 5: Specifications of the combined cycle [19].

\begin{tabular}{lc}
\hline Parameters & Value \\
\hline$m_{1}(\mathrm{~kg} / \mathrm{s})$ & 358.8 \\
$\eta_{s, P}$ & 0.85 \\
$T_{1}(\mathrm{~K})$ & 1179.1 \\
$T_{5}(\mathrm{~K})$ & 301 \\
$p_{1}(\mathrm{bar})$ & 67.6 \\
$\eta_{s, T}$ & 0.85 \\
$\eta_{s, C}$ & 0.85 \\
$T_{3}(\mathrm{~K})$ & 398.8 \\
$T_{7}(\mathrm{~K})$ & 855.4 \\
$p_{2}(\mathrm{bar})$ & 31.0 \\
\hline
\end{tabular}

The capital costs of the AWM system consist of the heat exchanger, pump, and turbine costs and are expressed as follows $[26,28]$ :

$$
\lg C_{b}=K_{1}+K_{2} \lg Z+K_{3}(\lg Z)^{2},
$$

where $C_{b}$ is the estimated component cost based on US dollars in the year of 1996. $Z$ is a parameter related to cycle components. For the heat exchanger, $Z$ refers to the area of heat exchanger, $A$. For the pump, $Z$ means the power consumption in pump, $W_{p}$. For the turbine, $Z$ represents the power output, $W_{\text {out }}$. The coefficients of $K_{1}, K_{2}$, and $K_{3}$ are listed in Table 4.

The capital cost $C$, which is corrected according to the component materials and the pressure, is determined by (8), as follows:

$$
C=C_{b} F_{b m}
$$

where the coefficient $F_{b m}$ is 3.5 for the turbine and the coefficients $F_{b m}$ for other components are calculated by (9) [29] as follows:

$$
F_{b m}=B_{1}+B_{2} F_{m} F_{p},
$$

where $B_{1}$ and $B_{2}$ are the coefficients of different types of the components and $F_{m}$ is the correction coefficient for the component materials. The values of $B_{1}, B_{2}$, and $F_{m}$ are presented in Table 4.

$F_{p}$ represents the pressure correction coefficient and is calculated by

$$
\lg F_{p}=C_{1}+C_{2} \times \lg p+C_{3} \times(\lg p)^{2} .
$$

The coefficients of $C_{1}, C_{2}$, and $C_{3}$ are also shown in Table 4.
Thus, the cost of the AWM system in the year 1996 $C_{\mathrm{AWM}, 1996}$ can be evaluated as follows:

$$
C_{\mathrm{AWM}, 1996}=C_{H}+C_{E}+C_{p}
$$

According to the time value of money, the cost of closed Brayton system in the year of 2006 and the AWM system in the year of 1996 are converted into the capital costs in the year of 2015, respectively, and the total cost of the combined cycle $\left(C_{2015}\right)$ is their sum, as follows:

$$
C_{2015}=C_{B, 2006} \frac{\mathrm{CEPCI}_{2015}}{\mathrm{CEPCI}_{2006}}+C_{\mathrm{AWM}, 1996} \frac{\mathrm{CEPCI}_{2015}}{\mathrm{CEPCI}_{1996}},
$$

where $\mathrm{CEPCI}_{1996}, \mathrm{CEPCI}_{2006}$, and $\mathrm{CEPCI}_{2015}$ are the chemical plant cost indexes in the years 1996, 2006, and 2015, and the values are 382,510 , and 592, respectively [30].

The capital recovery factor (CRF) is defined as follows:

$$
\mathrm{CRF}=\frac{i(1+i)^{T_{s}}}{(1+i)^{T_{s}}-1} .
$$

In this equation, $i$ is the discount rate and is $5 \%$ with inflation rate zero [21]. The economic life of the combined system $\left(T_{s}\right)$ is 40 years.

For each year, the operation hour of the system is calculated as follows:

$$
\mathrm{OP}_{s}=365 \times 24 \times L_{f} .
$$

In the combined system, the levelized energy cost (LEC) can be calculated by (14). One has

$$
\mathrm{LEC}=\frac{\mathrm{CRF} \times \mathrm{C}_{2015}+\mathrm{COM}_{s}}{\left(W_{\text {net }}+W_{\text {cool }}\right) \times \mathrm{OP}_{s}},
$$

where $\mathrm{COM}_{s}$ is the system operation and maintenance cost and is $1.5 \%$ of $C_{2015}$. The load factor $L_{f}$ is taken as 0.75 [31].

3.3. Optimization Model. A simple thermodynamic optimization or economical optimization might draw different results, because it is difficult to ensure a global costeffective cycle design. Thus, the optimizations on both the thermodynamics and economics are simultaneously needed in the assessment of the combined cycle. Regarding this, overall efficiency $\eta_{\text {overall,Combinedcycle }}$ and levelized energy cost (LEC) are selected to build a multiobjective function as the performance indicator in this paper. The multiobjective optimization model is constructed as follows.

The first objective function $F_{1}(X)$ is expressed by the following:

$$
\min \quad F_{1}(X)=\frac{1}{\eta_{\text {overall,Combinedcycle }}} .
$$




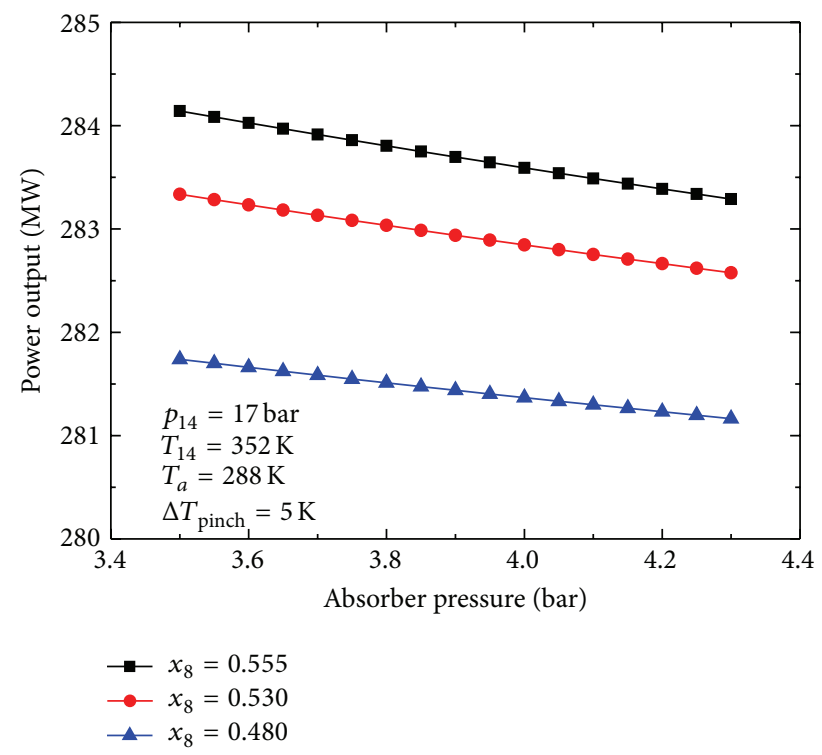

FIGURE 2: Variation of power output of combined cycle with absorber pressure.

The second objective function $F_{2}(X)$ is expressed by the following:

$$
\min \quad F_{2}(X)=\text { LEC. }
$$

The first objective function $F_{1}(X)$ represents system thermodynamic property, and the second objective function $F_{2}(X)$ is the thermoeconomic property.

In this paper, the method of linear weighted evaluation function is adopted to solve the objective function optimization model [28], which contains more than two performance indicators. The multiobjective function $F(X)$ is given by the following:

$$
F(X)=\alpha F_{1}(X)+\beta F_{2}(X)
$$

where $\alpha$ and $\beta$ are the weight coefficients of objective function and a method proposed bу Карлевиц is applied to solve these two weight coefficients [32]:

$$
\begin{aligned}
& \alpha=\frac{\left(F_{2}^{1}-F_{2}^{2}\right)}{\left[\left(F_{1}^{2}-F_{1}^{1}\right)+\left(F_{2}^{1}-F_{2}^{2}\right)\right]}, \\
& \beta=\frac{\left(F_{1}^{2}-F_{1}^{1}\right)}{\left[\left(F_{1}^{2}-F_{1}^{1}\right)+\left(F_{2}^{1}-F_{2}^{2}\right)\right]} .
\end{aligned}
$$

\section{Results and Discussion}

4.1. Effect of Absorber Pressure. The absorber pressure is the outlet pressure of ammonia-water turbine. If the absorber pressure is high, the working fluid cannot expand fully in the turbine, and both the power output and overall efficiency decrease in turn (Figures 2 and 3). Figure 4 shows that LEC increases with increasing absorber pressure. The reason is

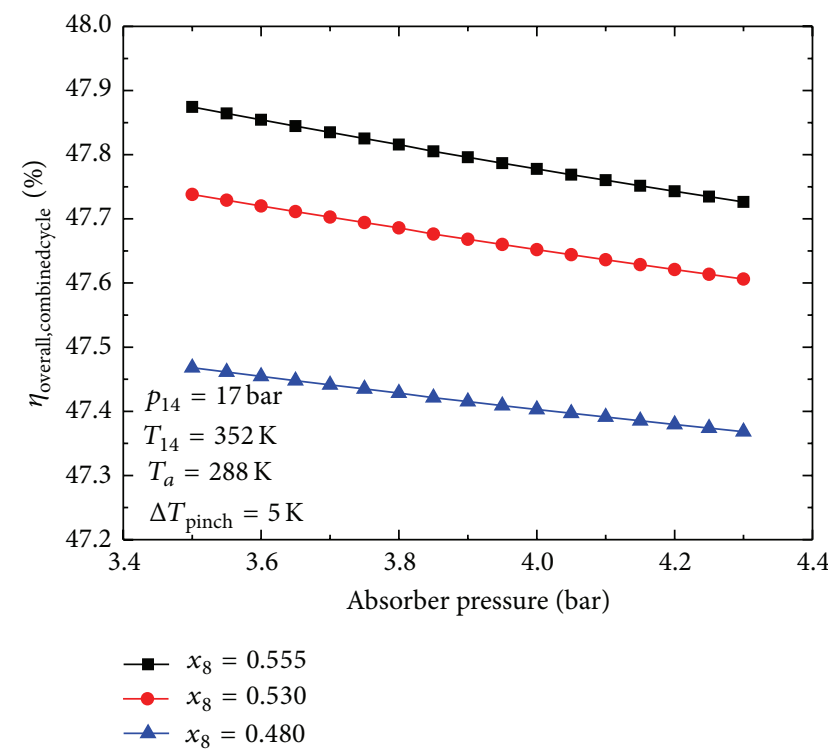

FIGURE 3: Variation of overall efficiency of combined cycle with absorber pressure.

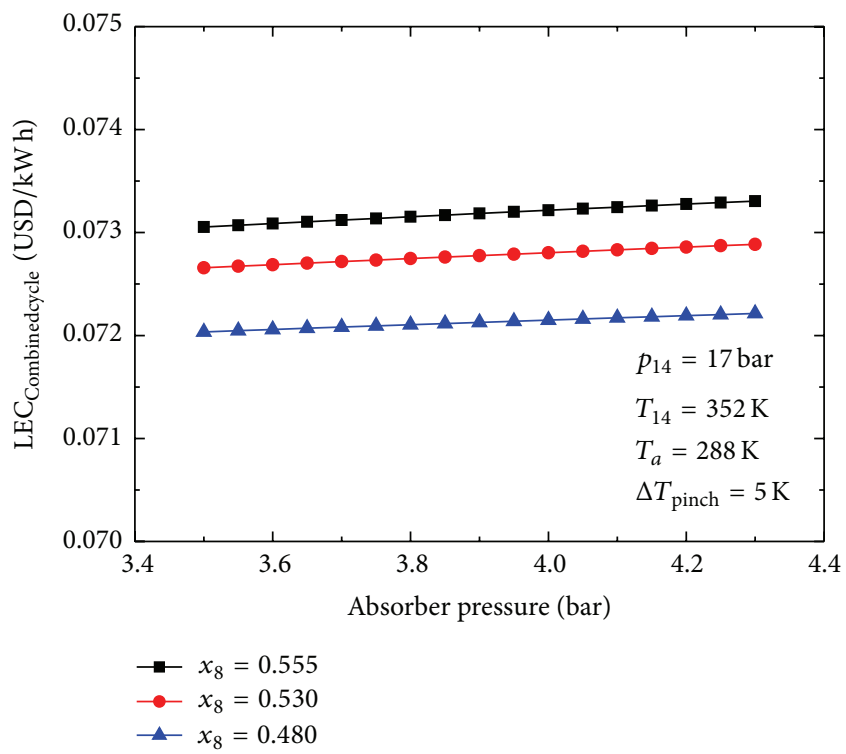

FIGURE 4: Variation of LEC of combined cycle with absorber pressure.

that the higher absorber pressure leads to less power output, which causes the increase in LEC. However, if absorber pressure is far less than 3.5 bar, the working fluid at the outlet of the absorber will change into vapor-liquid mixture. This increases the pump power consumption greatly. The relationships of $F(X)$ with the absorber pressure are demonstrated in Figure 5. $F(X)$ increases monotonically with increasing absorber pressure. Because the lowest $F(X)$ means the best performance, the lower absorber pressure is beneficial for the thermodynamic and economic performances. 


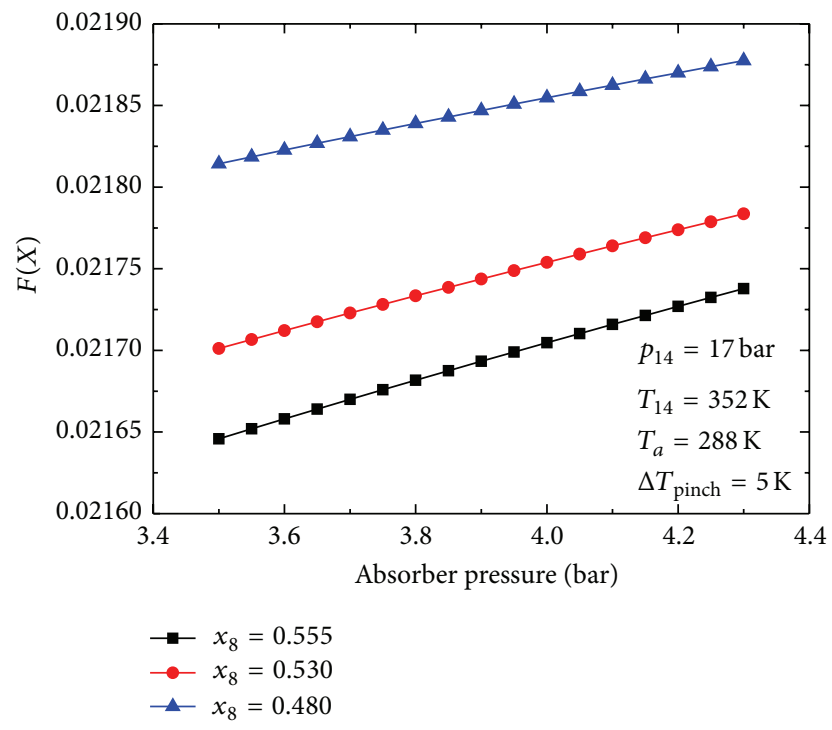

Figure 5: Variation of $F(X)$ of combined cycle with absorber pressure.

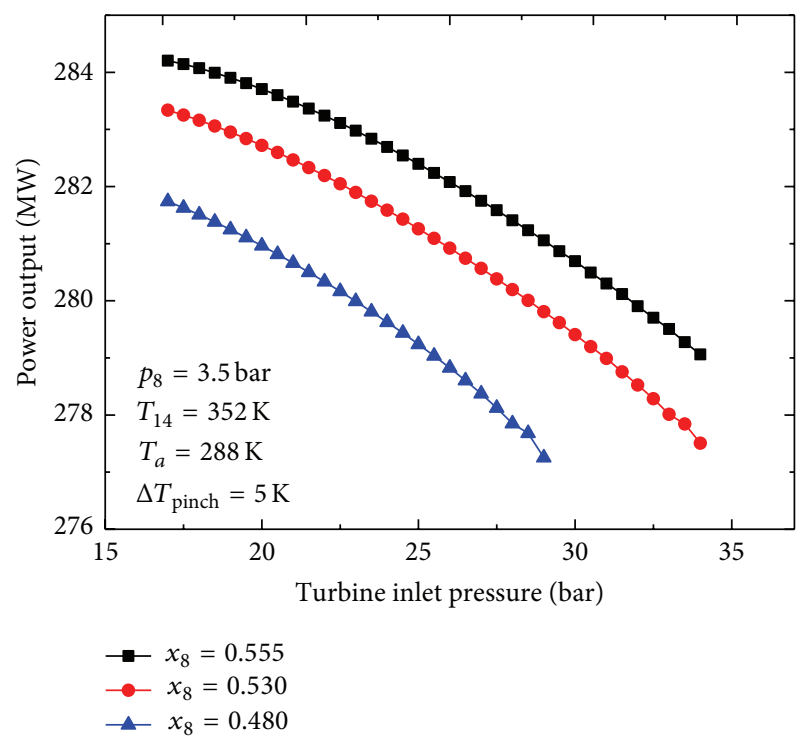

FIGURE 6: Variation of power output of combined cycle with turbine inlet pressure.

4.2. Effect of Turbine Inlet Pressure. As shown in Figures 6 and 7 , the variations of the power output and overall efficiency with the turbine inlet pressure are presented. The enthalpy drop across the turbine increases as the turbine inlet pressure increases. However, the enthalpy gains because of increasing turbine inlet pressure cannot compensate for the drop in the vapor flow rate. Thus, the turbine work output decreases. Owing to the decrease of vapor flow rate, both the cooling capacity and the equivalent work of cooling capacity $\left(W_{\text {cool }}\right)$ increase first and then decrease. However, the equivalent work of cooling capacity is too little compared with the power output of the combined cycle. Hence, the power output and overall efficiency decrease with the increasing turbine inlet temperature.

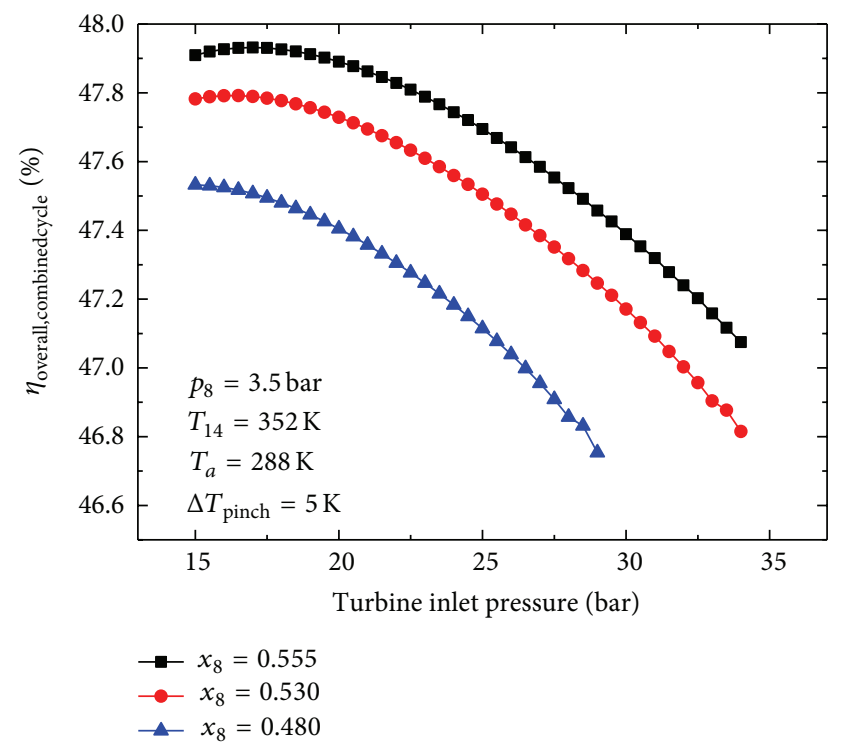

FIGURE 7: Variation of overall efficiency of combined cycle with turbine inlet pressure.

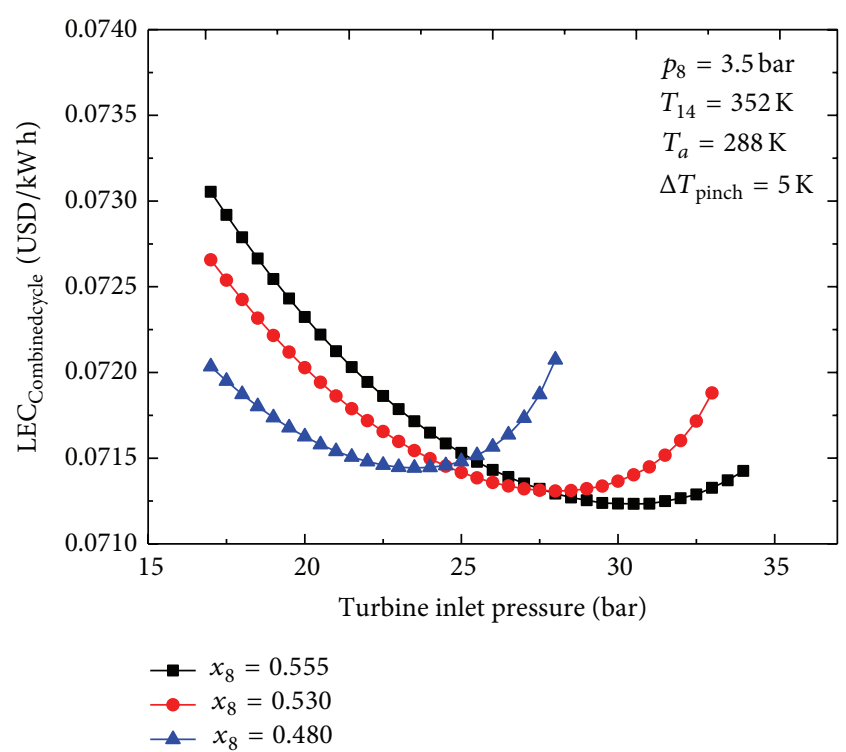

FIGURE 8: Variation of LEC of combined cycle with turbine inlet pressure.

As shown in Figure 8, LEC decreases at first and then increases with increasing turbine inlet pressure. When the ammonia mass fraction is 0.555 , LEC reaches the minimum of $0.0712 \mathrm{USD} /(\mathrm{kWh})$ with the turbine inlet pressure of 30.5 bar. Figure 9 shows that $F(X)$ decreases first and increases with the increasing turbine inlet pressure when the ammonia mass fraction is 0.53 or 0.555 . Thus, an optimal turbine inlet pressure is present, and the optimal turbine inlet pressure value is changing with the ammonia mass fraction.

4.3. Effect of Turbine Inlet Temperature. Figure 10 shows that the power output increases with increasing turbine 


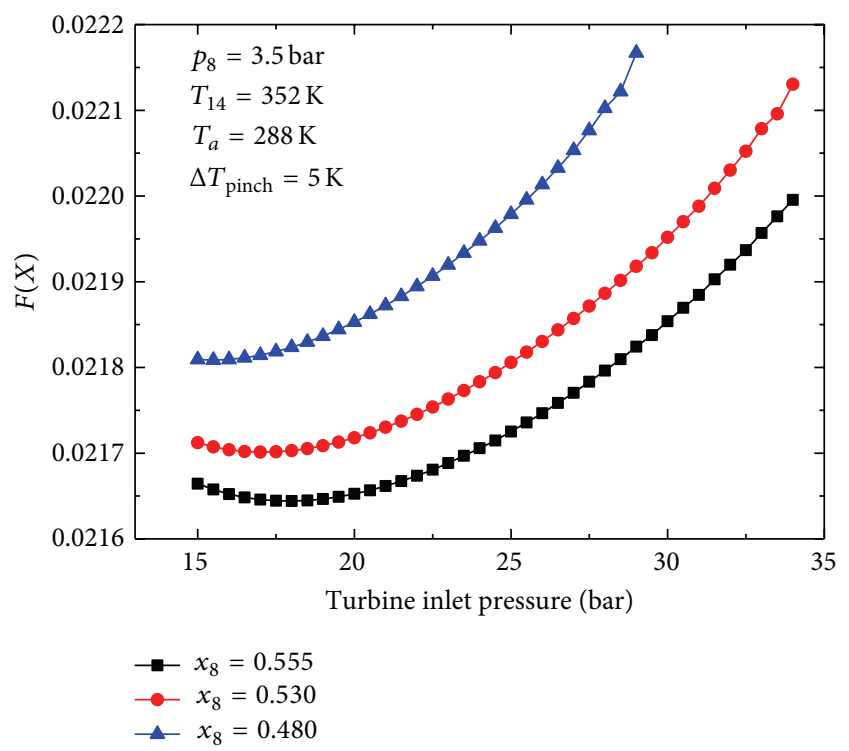

FIGURE 9: Variation of $F(X)$ of combined cycle with turbine inlet pressure.

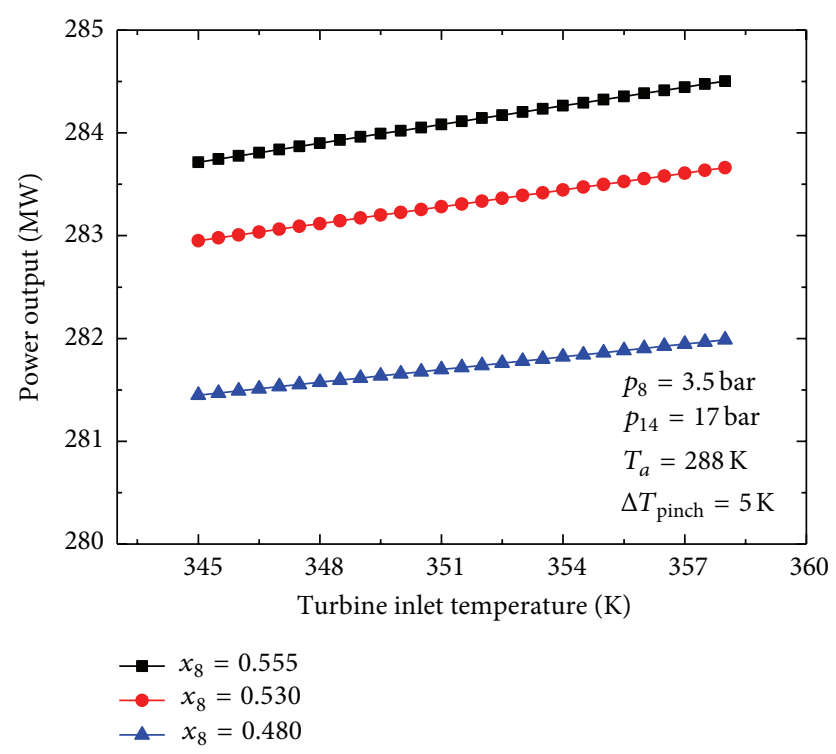

FIGURE 10: Variation of power output of combined cycle with turbine inlet temperature.

inlet temperature. With fixed pressure ratio, increase in inlet temperature leads to higher inlet enthalpy of working fluid. The exit enthalpy of working fluid also increases at the same time because of high exit temperature. But the increase in enthalpy caused by the increase in inlet temperature is more than that because of the increase in exit temperature. Hence, the turbine work output rises up as the turbine inlet temperature increases.

Because the increasing turbine inlet temperature increases cooler inlet temperature, the equivalent work of cooling capacity $\left(W_{\text {cool }}\right)$ declines. However, the increase of power output compensates for the drop in the equivalent

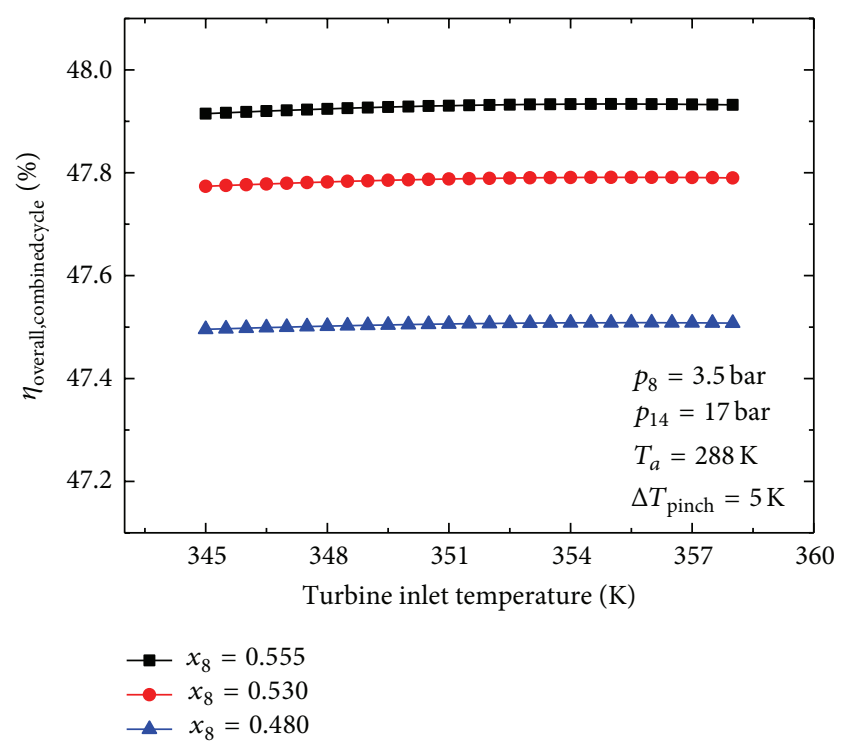

FIGURE 11: Variation of overall efficiency of combined cycle with turbine inlet temperature.

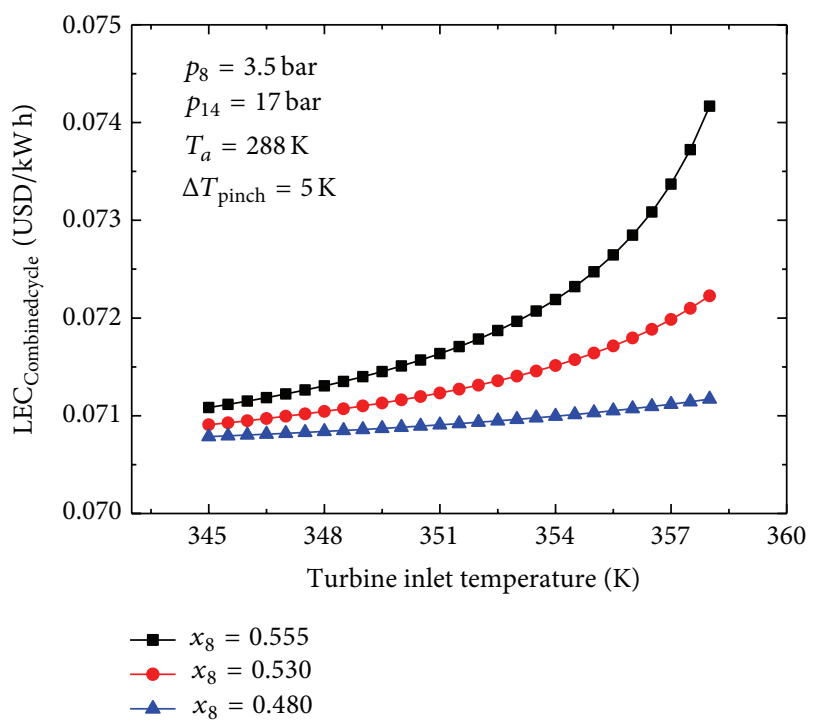

FIGURE 12: Variation of LEC of combined cycle with turbine inlet temperature.

work of cooling capacity. This fact results in the slight increase of overall efficiency (Figure 11).

As shown in Figure 12, LEC increases with increasing turbine inlet temperature monotonously. This fact implies that the lower inlet temperature results in better economic performance. Figure 13 shows that $F(X)$ changes very slightly when the turbine inlet temperature is lower than $253 \mathrm{~K}$.

4.4. Effect of Ammonia Mass Fraction. Figures 14 and 15 reveal that the power output and overall efficiency will benefit from increased ammonia mass fraction. Increasing the ammonia mass fraction will improve the thermodynamic performance of the combined cycle because the higher the ammonia 


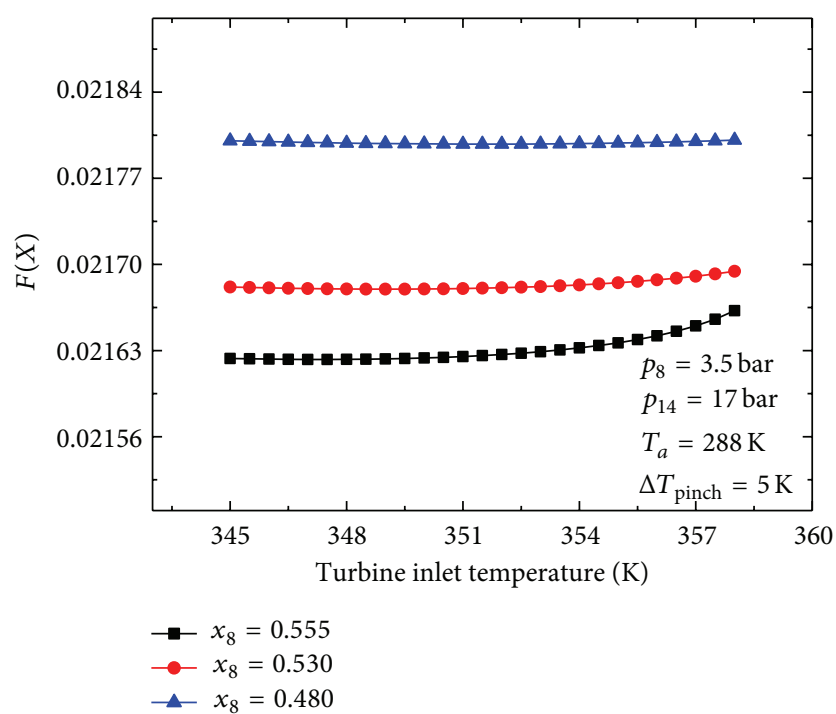

FIGURE 13: Variation of $F(X)$ of combined cycle with turbine inlet temperature.

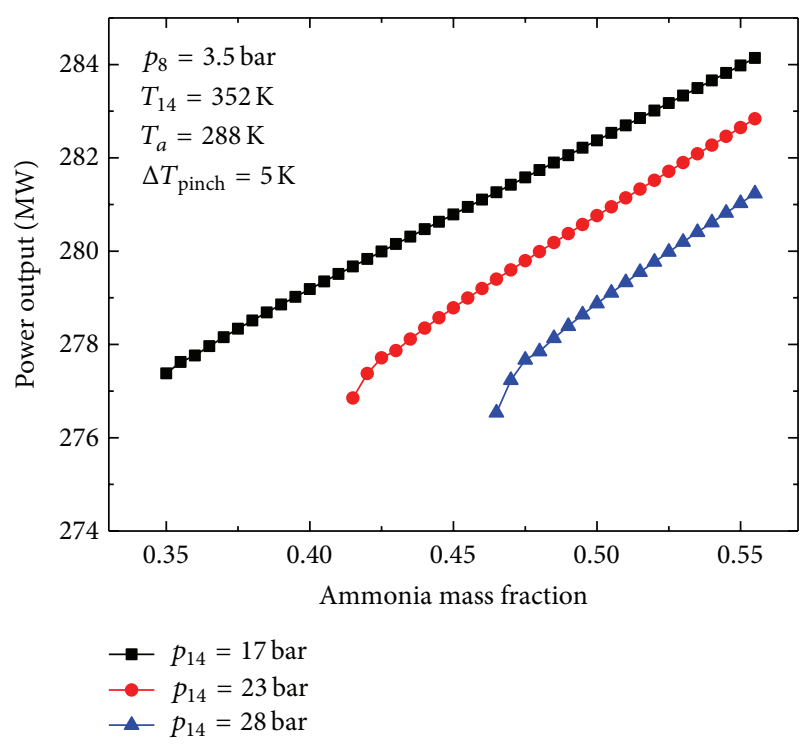

FIGURE 14: Variation of power output of combined cycle with ammonia mass fraction.

concentration, the greater the ammonia vapor flow rate expanding in the turbine. However, if the ammonia mass fraction is too high, the pump power consumption will increase greatly because the ammonia liquid mixture at the outlet of the absorber (state 8) will change into the vaporliquid mixture.

Figure 16 shows the effect of ammonia mass fraction on LEC. With the increase of ammonia mass fraction, LEC decreases initially and then increases. The higher the turbine inlet pressure, the smaller the optimal ammonia mass fraction. When the turbine inlet pressure is 17 bar, LEC reaches the minimum of $0.0716 \mathrm{USD} /(\mathrm{kWh})$ with an ammonia mass fraction of 0.405 . When the turbine inlet pressure is 17 bar, LEC reaches the minimum of $0.0713 \mathrm{USD} /(\mathrm{kWh})$ with

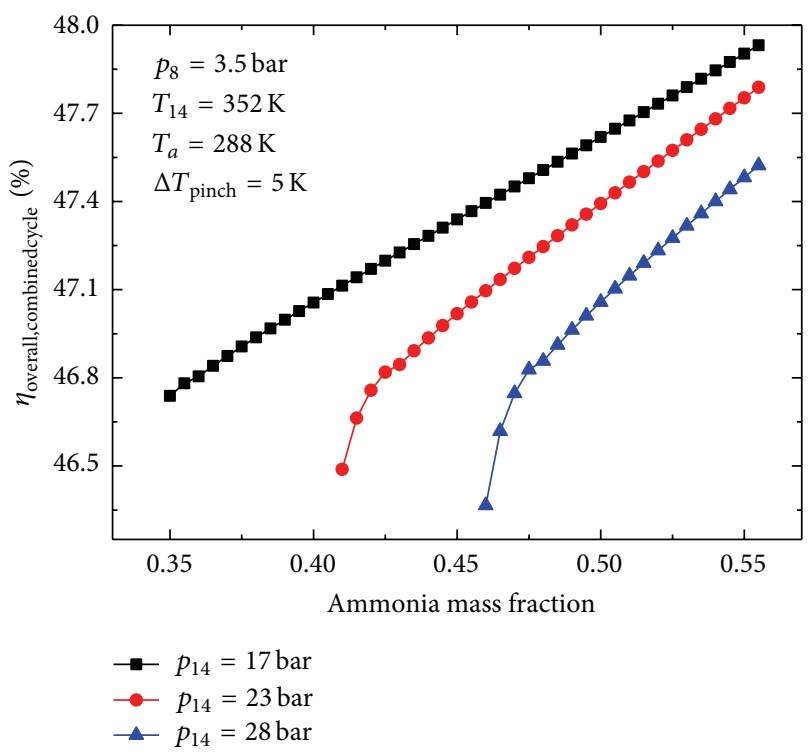

FIGURE 15: Variation of overall efficiency of combined cycle with ammonia mass fraction.

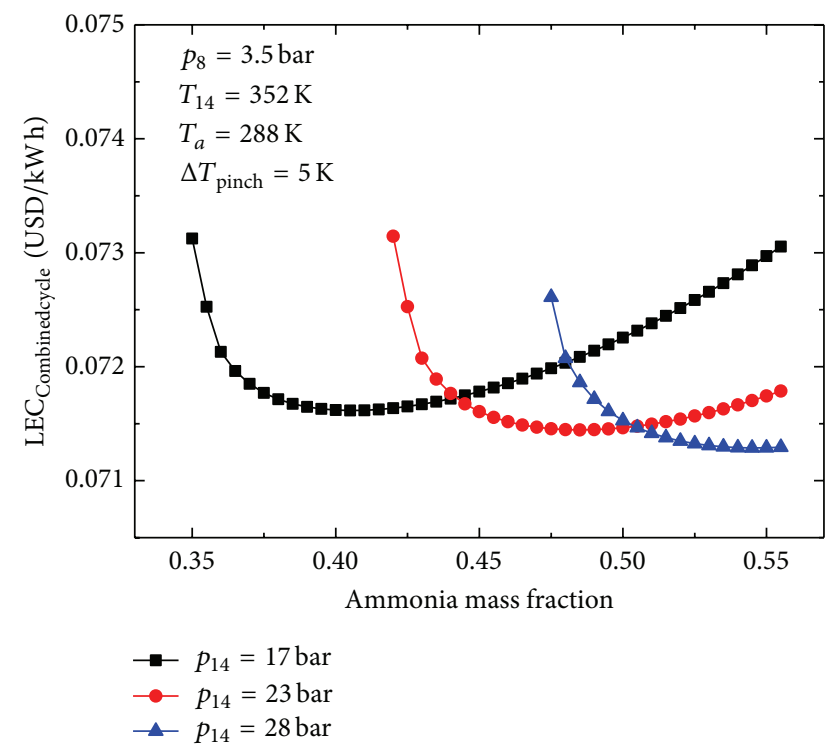

FIGURE 16: Variation of LEC of combined cycle with ammonia mass fraction.

an ammonia mass fraction of 0.545 . Figure 17 presents the variations of $F(X)$ with ammonia mass fraction. $F(X)$ decreases rapidly with increasing ammonia mass fraction.

4.5. System Optimization. In this work, SA (Simulated Annealing) is employed to obtain the optimum combination of the key parameters. For the optimization, the constraints are simplified as follows:

Subject to:

$$
\begin{aligned}
& 17.0 \leqslant p_{14}(\text { bar }) \leqslant 34.0, \\
& 345 \leqslant T_{14}(\mathrm{~K}) \leqslant 375, \\
& 0.36 \leqslant x_{8} \leqslant 0.555
\end{aligned}
$$




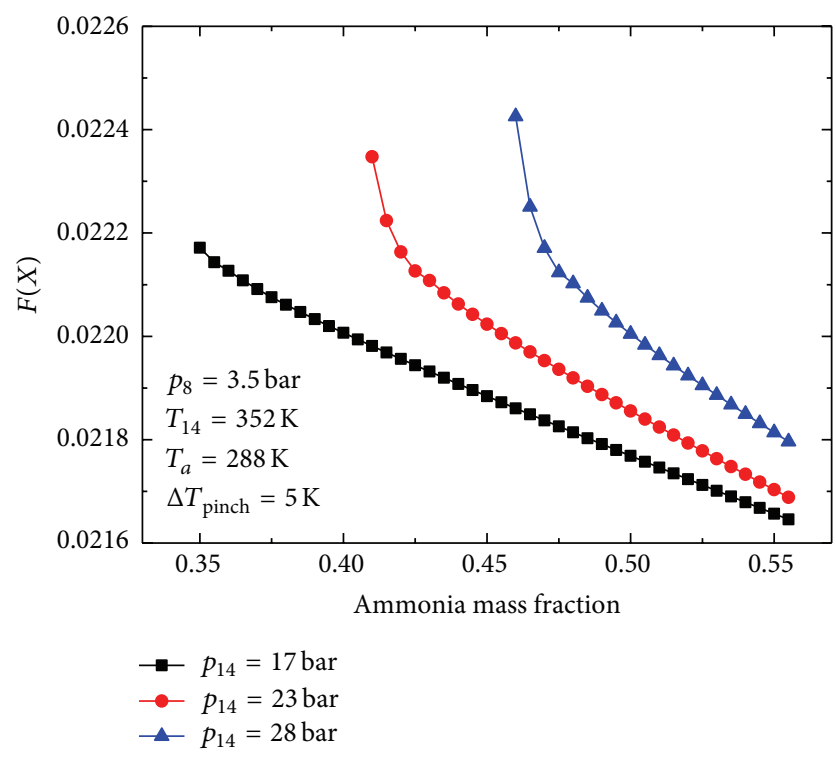

FIGURE 17: Variation of $F(X)$ of combined cycle with ammonia mass fraction.

$$
\begin{aligned}
288 & \leqslant T_{a}(\mathrm{~K}) \leqslant 300, \\
0 & \leqslant \frac{m_{10}}{m_{9}} \leqslant 1, \\
0 & \leqslant \frac{m_{12}}{m_{1}} \leqslant 1, \\
\left(T_{17}-T_{10}\right) & \geqslant 5 \mathrm{~K}, \\
\left(T_{4}-T_{11}\right) & \geqslant 5 \mathrm{~K}, \\
\left(T_{3}-T_{\text {Boiler }}\right) & \geqslant 5 \mathrm{~K}, \\
T_{\text {Boiler }} & \geqslant T_{\text {Rectifier }}, \\
Q_{\text {cool }} & >0 \\
p_{14} & \geqslant p_{8} .
\end{aligned}
$$

The selection of the above-mentioned parameters for this optimization is according to the literatures $[6,9,13]$.

Table 6 shows some results of the closed Brayton cycle. To compare the thermodynamic and economic performances of the combined cycle with those of the closed Brayton cycle, three parameters are defined as follows:

$$
\begin{aligned}
\mathrm{RV}_{W_{\text {net }}} & =\frac{\left(W_{\text {net,Combinedcycle }}-W_{\text {net,Brayton }}\right)}{W_{\text {net,Brayton }}}, \\
\mathrm{RV}_{\eta_{\text {overall }}} & =\frac{\left(\eta_{\text {overall,Combinedcycle }}-\eta_{\text {overall,Brayton }}\right)}{\eta_{\text {overall,Brayton }}}, \\
\mathrm{RV}_{\mathrm{LEC}} & =\frac{\left(\mathrm{LEC}_{\text {Combinedcycle }}-\mathrm{LEC}_{\text {Brayton }}\right)}{\text { LEC }_{\text {Brayton }}} .
\end{aligned}
$$

TABLE 6: Results of the closed Brayton cycle.

\begin{tabular}{lc}
\hline Parameters & Value \\
\hline$Q_{\text {core }}(\mathrm{MW})$ & 593.64 \\
$\eta_{\text {overall, } B}(\mathrm{MW})$ & $46.6 \%$ \\
$W_{\text {net, } B}(\mathrm{USD} /(\mathrm{kWh}))$ & 276.90 \\
$\mathrm{LEC}_{B}(\mathrm{k})$ & 0.0711 \\
\hline
\end{tabular}

TABLE 7: Optimization results.

\begin{tabular}{ll}
\hline Parameters & Optimization results \\
\hline & $F(X)=0.02164$ \\
& $W_{\text {net,Combinedcycle }}=283.56 \mathrm{MW}$, \\
& $\mathrm{RV}_{W_{\text {net }}}=2.41 \%$ \\
$\Delta T_{\text {pinch }}=5 \mathrm{~K}, p_{8}=3.5 \mathrm{bar}$ & $\eta_{\text {overall,Combinedcycle }}=47.91 \%, \mathrm{RV}_{\eta_{\text {overall }}}$ \\
$p_{14}=18.1 \mathrm{bar}, T_{14}=345 \mathrm{~K}$ & $=2.43 \%$ \\
$x_{8}=0.555$ & $\mathrm{LEC}_{\text {Combinedcycle }}=$ \\
& $0.0706 \mathrm{USD} /(\mathrm{kWh}), \mathrm{RV}_{\mathrm{LEC}}=$ \\
& $-0.73 \%$ \\
\hline
\end{tabular}

Table 7 lists the result of the parameters for the optimization. The optimized power output and overall efficiency for the combined cycle are $283.56 \mathrm{MW}$ and $47.91 \%$, respectively. These values are $2.41 \%$ and $2.43 \%$ higher than those of the closed Brayton cycle, respectively. Both the lower average heat addition temperature and the higher back pressure of turbine in AWM cycle result in less power output and lower overall efficiency of the combined cycle.

Comparing with closed Brayton cycle, the combined cycle reduces the LEC slightly. The optimized LEC of combined cycle is $0.73 \%$ lower than that of the closed Brayton cycle. The reason is that the AWM utilizes the waste heat and adds the power output and the cooling capacity to the closed Brayton cycle. However, the total capital investment increases due to the combined AWM system.

\section{Conclusions}

In this paper, a combined cycle, which combines AWM cycle and a nuclear closed Brayton cycle to recover the waste heat rejected from the precooler, is proposed. A detailed parametric study and optimization are carried out for this combined cycle according to the thermodynamics and economics performances. The combined cycle can potentially be used to improve the power output and overall efficiency. The power output and overall efficiency of the combined cycle increase with increasing turbine inlet temperature and ammonia mass fraction, but the turbine inlet temperature and the ammonia mass fraction are limited by the heat source temperature and the absorb pressure, respectively. Compared with the closed Brayton cycle, the optimized power output and overall efficiency increase by $2.41 \%$ and $2.43 \%$, respectively. LEC increases with decreasing absorber pressure and turbine inlet temperature. The optimized LEC of the combined cycle is $0.0706 \mathrm{USD} /(\mathrm{kWh})$, which is $0.73 \%$ lower than those of the closed Brayton cycle. 


\section{Competing Interests}

The authors declare that there are no competing interests regarding the publication of this paper and regarding the funding that they have received.

\section{Acknowledgments}

This present research was supported by the Chinese Natural Science Fund (Project no. 51306216) and the Fundamental Research Funds for the Central University (Project no. CDJ2R13140016).

\section{References}

[1] A. Soroureddin, A. S. Mehr, S. M. S. Mahmoudi, and M. Yari, "Thermodynamic analysis of employing ejector and organic Rankine cycles for GT-MHR waste heat utilization: A Comparative Study," Energy Conversion and Management, vol. 67, pp. 125-137, 2013.

[2] S. Dardour, S. Nisan, and F. Charbit, "Utilisation of waste heat from GT-MHR and PBMR reactors for nuclear desalination," Desalination, vol. 205, no. 1-3, pp. 254-268, 2007.

[3] A. I. Kalina, "Combined-cycle system with novel bottoming cycle," Journal of Engineering for Gas Turbines and Power, vol. 106, no. 4, pp. 737-742, 1984.

[4] D. Y. Goswami, "Solar thermal power technology: present status and ideas for the future," Energy Sources, vol. 20, no. 2, pp. 137145,1998 .

[5] D. S. Ayou, J. C. Bruno, R. Saravanan, and A. Coronas, "An overview of combined absorption power and cooling cycles," Renewable and Sustainable Energy Reviews, vol. 21, pp. 728-748, 2013.

[6] R. V. Padilla, G. Demirkaya, D. Y. Goswami, E. Stefanakos, and M. M. Rahman, "Analysis of power and cooling cogeneration using ammonia-water mixture," Energy, vol. 35, no. 12, pp. 4649-4657, 2010.

[7] S. Lu and D. Y. Goswami, "Optimization of a novel combined power/refrigeration thermodynamic cycle," Journal of Solar Energy Engineering, vol. 125, no. 2, pp. 212-217, 2003.

[8] M. Pouraghaie, K. Atashkari, S. M. Besarati, and N. Narimanzadeh, "Thermodynamic performance optimization of a combined power/cooling cycle," Energy Conversion and Management, vol. 51, no. 1, pp. 204-211, 2010.

[9] G. Demirkaya, R. Vasquez Padilla, D. Y. Goswami, E. Stefanakos, and M. M. Rahman, "Analysis of a combined power and cooling cycle for low-grade heat sources," International Journal of Energy Research, vol. 35, no. 13, pp. 1145-1157, 2011.

[10] L. S. Vieira, J. L. Donatelli, and M. E. Cruz, "Exergoeconomic improvement of a complex cogeneration system integrated with a professional process simulator," Energy Conversion and Management, vol. 50, no. 8, pp. 1955-1967, 2009.

[11] Z. Shengjun, W. Huaixin, and G. Tao, "Performance comparison and parametric optimization of subcritical Organic Rankine Cycle (ORC) and transcritical power cycle system for lowtemperature geothermal power generation," Applied Energy, vol. 88, no. 8, pp. 2740-2754, 2011.

[12] T. Guo, H. X. Wang, and S. J. Zhang, "Fluids and parameters optimization for a novel cogeneration system driven by lowtemperature geothermal sources," Energy, vol. 36, no. 5, pp. 2639-2649, 2011.
[13] A. Coskun, A. Bolatturk, and M. Kanoglu, "Thermodynamic and economic analysis and optimization of power cycles for a medium temperature geothermal resource," Energy Conversion and Management, vol. 78, pp. 39-49, 2014.

[14] V. Zare, S. M. S. Mahmoudi, and M. Yari, "On the exergoeconomic assessment of employing Kalina cycle for GT-MHR waste heat utilization," Energy Conversion and Management, vol. 90, pp. 364-374, 2015.

[15] K. Bahlouli, R. Khoshbakhti Saray, and N. Sarabchi, "Parametric investigation and thermo-economic multi-objective optimization of an ammonia-water power/cooling cycle coupled with an HCCI (homogeneous charge compression ignition) engine," Energy, vol. 86, pp. 672-684, 2015.

[16] Y. Feng, Y. Zhang, B. Li, J. Yang, and Y. Shi, "Sensitivity analysis and thermoeconomic comparison of ORCs (organicRankine cycles) for low temperature waste heat recovery," Energy, vol. 82, pp. 664-677, 2015.

[17] F. Xu, D. Y. Goswami, and S. S. Bhagwat, "A combined power/cooling cycle," Energy, vol. 25, no. 3, pp. 233-246, 2000.

[18] F. Xu and D. Y. Goswami, "Thermodynamic properties of ammonia-water mixtures for power-cycle applications," Energy, vol. 24, no. 6, pp. 525-536, 1999.

[19] M. S. El-Genk and J.-M. Tournier, "Noble gas binary mixtures for gas-cooled reactor power plants," Nuclear Engineering and Design, vol. 238, no. 6, pp. 1353-1372, 2008.

[20] F. W. Yu, K. T. Chan, R. K. Y. Sit et al., "Review of standards for energy performance of chiller systems serving commercial buildings," Energy Procedia, vol. 61, pp. 2778-2782, 2014.

[21] S. Nisan and S. Dardour, "Economic evaluation of nuclear desalination systems," Desalination, vol. 205, no. 1-3, pp. 231242, 2007.

[22] L. E. Herranz, J. I. Linares, and B. Y. Moratilla, "Power cycle assessment of nuclear high temperature gas-cooled reactors," Applied Thermal Engineering, vol. 29, no. 8-9, pp. 1759-1765, 2009.

[23] H. D. Madhawa Hettiarachchi, M. Golubovic, W. M. Worek, and Y. Ikegami, "Optimum design criteria for an Organic Rankine cycle using low-temperature geothermal heat sources," Energy, vol. 32, no. 9, pp. 1698-1706, 2007.

[24] Y. T. Zhu, W. H. Qu, and P. Y. Yu, Chemical Equipment Design Manual, Chemical Industry Press, 2005.

[25] Q. Songwen, Heat Exchanger Design Handbook, Chemical Industry Press, 2002.

[26] R. Turton, R. C. Bailie, W. B. Whiting et al., Analysis, Synthesis and Design of Chemical Processes, Prentice Hall, Upper Saddle River, NJ, USA, 1997.

[27] F. Táboas, M. Vallès, M. Bourouis, and A. Coronas, "Flow boiling heat transfer of ammonia/water mixture in a plate heat exchanger," International Journal of Refrigeration, vol. 33, no. 4, pp. 695-705, 2010.

[28] L. Xiao, S.-Y. Wu, T.-T. Yi, C. Liu, and Y.-R. Li, "Multi-objective optimization of evaporation and condensation temperatures for subcritical organic Rankine cycle," Energy, vol. 83, pp. 723-733, 2015.

[29] C. E. Campos Rodríguez, J. C. Escobar Palacio, O. J. Venturini et al., "Exergetic and economic comparison of ORC and Kalina cycle for low temperature enhanced geothermal system in Brazil," Applied Thermal Engineering, vol. 52, no. 1, pp. 109-119, 2013.

[30] D. Mignard, "Correlating the chemical engineering plant cost index with macro-economic indicators," Chemical Engineering Research and Design, vol. 92, no. 2, pp. 285-294, 2014. 
[31] http://www.neimagazine.com/news/newsnuclear-reactor-performance-by-vendors-agrs-23.

[32] H. W. Tang, Practical Introduction to Mathematical Programming, Dalian Institute of Technology Press, 1986.

[33] V. Zare, S. M. S. Mahmoudi, and M. Yari, "An exergoeconomic investigation of waste heat recovery from the Gas TurbineModular Helium Reactor (GT-MHR) employing an ammoniawater power/cooling cycle," Energy, vol. 61, pp. 397-409, 2013. 

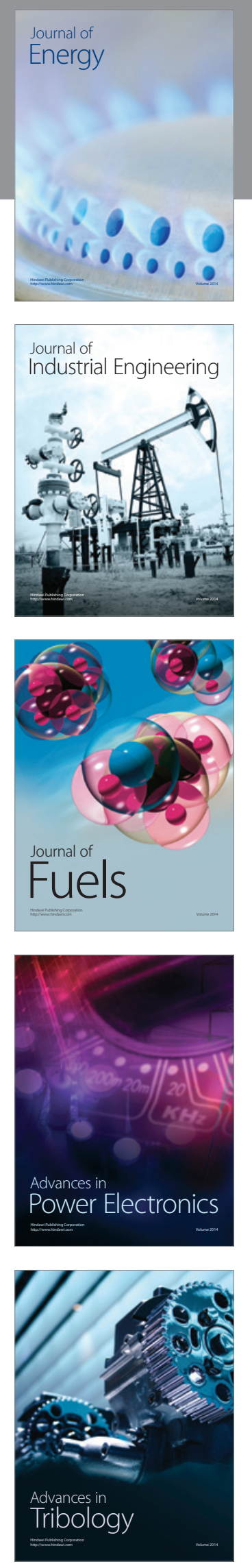
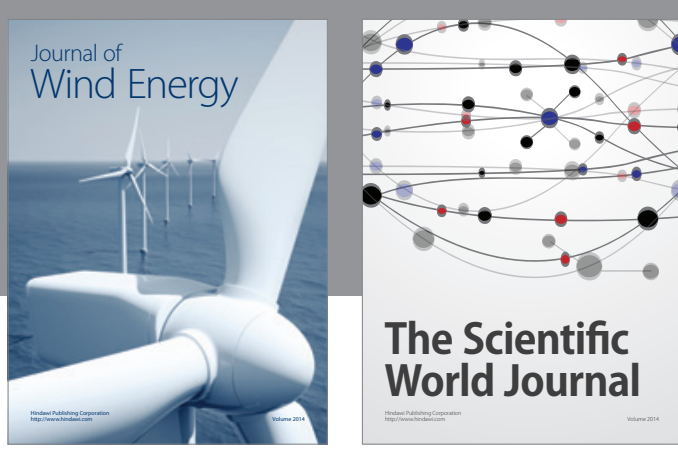

The Scientific World Journal
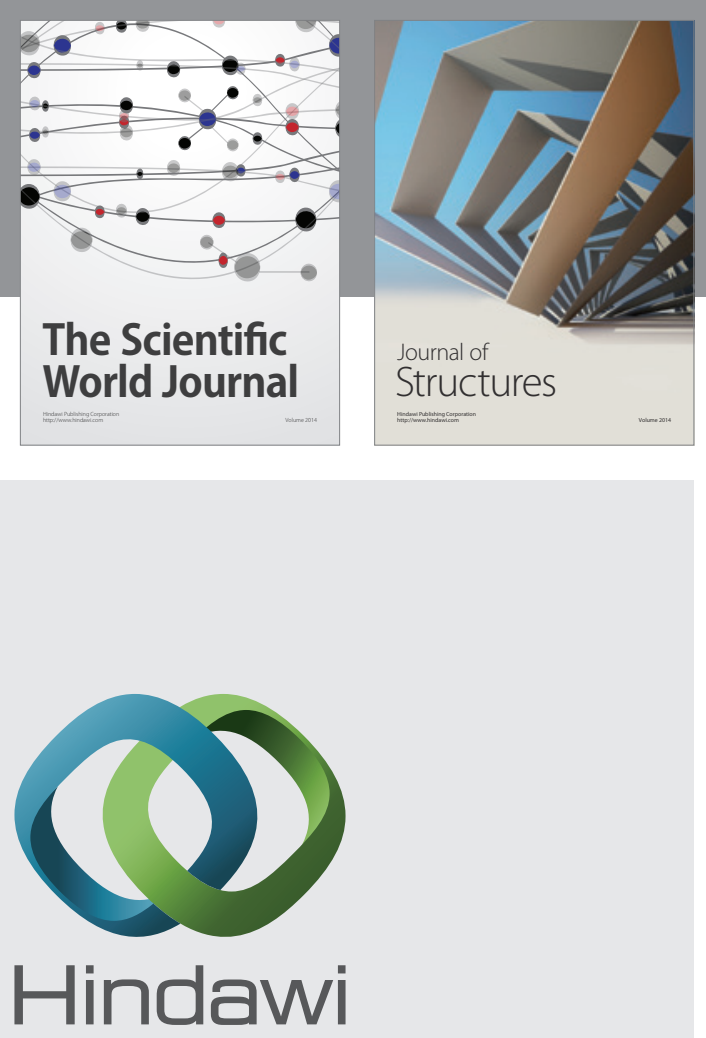

Submit your manuscripts at

http://www.hindawi.com
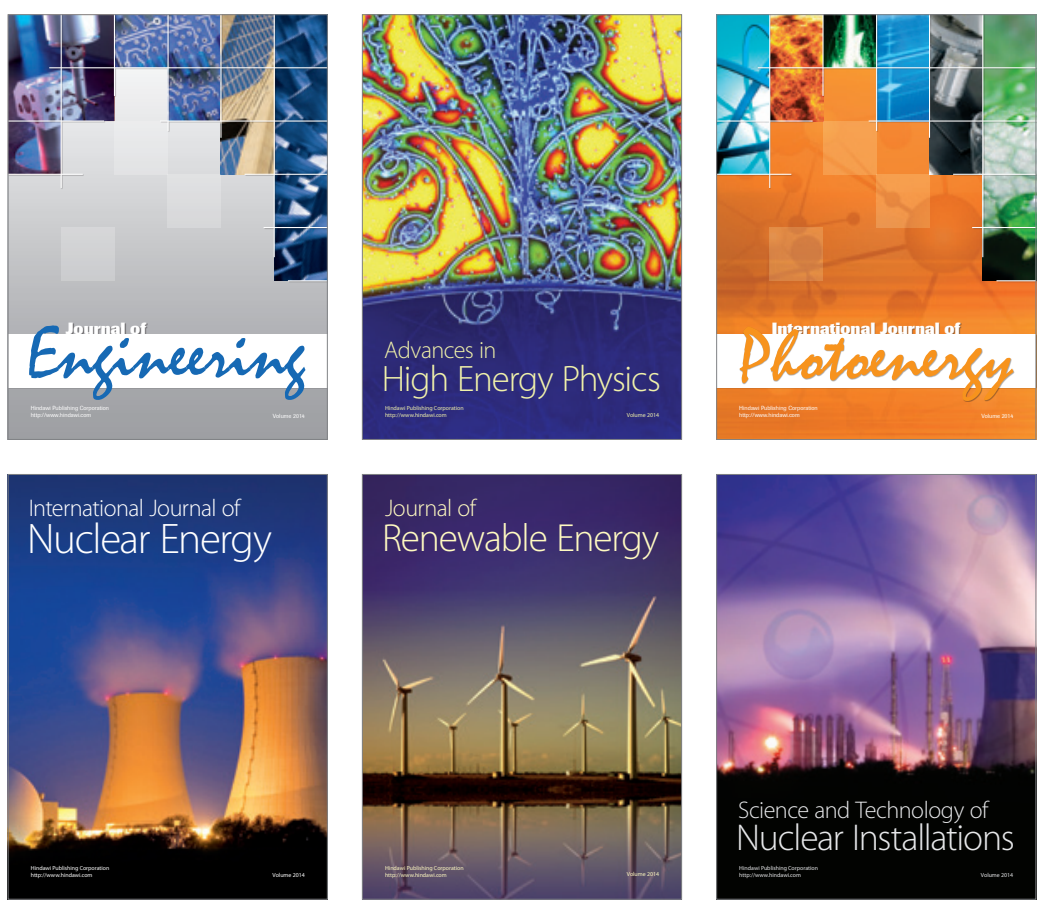
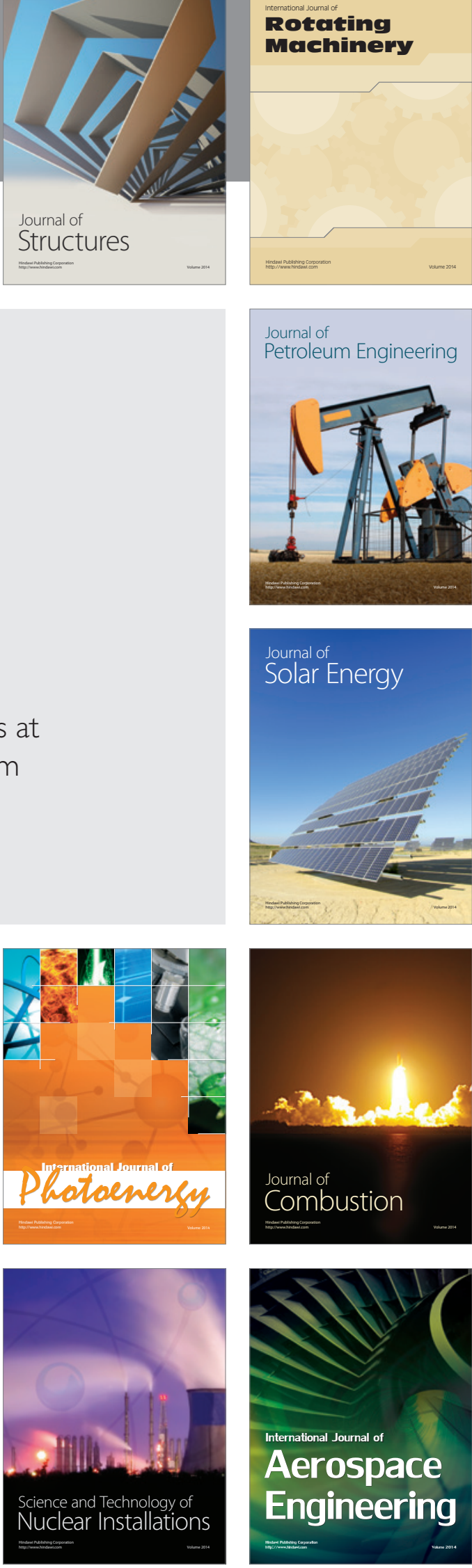